\title{
The Perceptions Of Higher Education Academic Staff On The Freedom To Decide What To Teach
}

\author{
Kimoga Joseph \\ College of Education and External Studies \\ Makerere University, Kampala - Uganda \\ Namaganda Justine \\ College of Education and External Studies \\ Makerere University, Kampala - Uganda \\ Maigut Tom \\ College of Education and External Studies \\ Makerere University, Kampala - Uganda \\ Asiimwe Constance \\ College of Education and External Studies \\ Makerere University, Kampala - Uganda \\ Ngabirano Caroline \\ College of Education and External Studies \\ Makerere University, Kampala - Uganda
}

\begin{abstract}
The common perception is that teachers have to teach according to what is laid out in the curriculum. Little is spent on reflecting on the effects of teaching a prescribed content to which design the practitioner did not contribute. This article is not refuting the existence of prescribed content for classroom interaction, but the freedom of the teacher in preferring parts of the content to teach. We set out to seek the perceptions of academic staff at higher education level on freedom to decide what to teach. We found that political interference is the major threat to the freedom of academic staff regarding the decision on the content. We conclude that there is lack of higher education policy regarding academic freedom to choose the content to teach, and there is also no specific internal policy to safeguard academic freedom. We recommend establishing institutional policies and national laws to foster academic freedom; promoting freedom of expression beyond constitutional rhetoric; and allowing free operation of higher education institutions.
\end{abstract}

Key words: academic freedom, academic staff, content

\section{INTRODUCTION}

Members of academic staff are of a profession of often intellectual risk takers, ahead of their time, and loyal to the truth. Thus the notion of academic freedom is invoked to justify their statements which at times may offend the institution, politicians, religious leaders, parents or students. This article focuses on how University polices and laws impact on the freedom of lecturers to decide what to teach. The study provides an insight in understanding the concept of academic freedom, conditions affecting academic staff freedom to decide what to teach and 
offer possible solutions that can allow academic staff to determine the kind of content to deliver to the learners.

\section{LITERATURE REVIEW}

Legally, the concept of academic freedom originated from Germany in 1850. It was known as "lehrfreiheit" to refer to the right of an academic staff to teach on any subject (Euben, [1]). The term academic freedom may differ according to context and authors. Caston [2] and Ashby [3] define academic freedom as the freedom of individual University lecturers to teach according to their conscience, convictions and to publish views on their own subject without any external interference. Furthermore, Brown [4] defines academic freedom as; the right of university academic staff and researchers to appropriately investigate fields of knowledge and express views without fear of restraint or reprisals. Searle [5] assumes that "most professors already know what academic freedom is; the problem is to defend it, not to analyse it or define it" (p. 169). This assumption creates confidence that academic staff is in position to pursue what they are aware of as their due. Therefore, academic freedom is not only the freedom of academic staff to conduct academic activities but also to express their views freely. Downs ([6], p4) explains academic freedom as "the freedom of scholars to pursue the truth in a manner consistent with professional standards of inquiry". Therefore, the freedom to decide what to teach is fundamental to the advancement of truth and for the protection of the rights of academic staff in teaching. In fact, academic freedom as 0'Hear, [7] observes, amounts to no more than a right supposedly given to academics to say and teach what they believe to be true. On the contrary, Shils [8]) points out that, academic freedom is not the freedom of academic individuals to do just anything, to follow any impulse or desire, or to say anything that occurs to them. It is the freedom to do academic things: to teach the truth as they see it on the basis of prolonged and intensive study, to discuss their ideas freely with their colleagues, to publish the truth as they have arrived at it by systematic methodical research and assiduous analyses. That is academic freedom proper. It is the liberty to access or disseminate information without any constraint (Lee, [9]). In this regard therefore, academic freedom is an individual right of academic staff, not so much a personal privilege but a condition of work where academic staff seek and transmit the truth. Institutions of Higher Education are conducted for the common good and not to further the interests of either the individual teacher or the institution as a whole but to perform academic activities regarding their knowledge of subject matter and the freedom to share their views with their colleagues.

The whole rationale of academic freedom rotates around the fact of one's ability to choose an area from the course content, teach in their area of competence, and carry out research in the fields of their academic interest. This establishes the right of academic staff to remain true to his or her pedagogical philosophy and intellectual commitment (Nelson, [10]). In this regard therefore, academic freedom connotes the freedom of academic staff from outside interference with regard to the selection of teaching content and the right to establish the curricula according to which the students will be given instructions. The study assumption is that, academic staff should have the freedom to exercise their academic commitments after all they are specialists or technocrats in their areas of specialization. And therefore, should be free to deliver to students the content they think is vital and more competitive even after graduation.

Academic freedom has a long and controversial history. However, as Fuchs [11] and Altbach [12] remark, following several struggles, and especially with the rise of the research-based universities in early $19^{\text {th }}$ century, freedom of expression gradually expanded and professors were given more latitude in teaching and research. This ushered in the modern concept of academic freedom in the United States. With the rise of ideological conflicts, especially relating to economic theory, academic staff began to feel the need for protection against trustees or 
administrators who sought the dismissal of academic staff whose views they found unpalatable. The academic freedom of the teacher comprises of three elements; freedom of inquiry and research, freedom of teaching within the university or college, and freedom of extramural utterance and action. This suggests that the university must protect academic staff from external threats of public opinion. It should be an intellectual platform where new ideas may germinate and their fruits ripen.

In the post-cold war era, most African countries re-embraced human rights and democracy, which grants equal opportunities and respects democratic principles. These countries have undertaken significant innovations in their higher education system such as; internationalization, privatization and massification (Adar, [13]). In the face of deliberate violations of academic freedom in the past, African scholars have come up with legal documents like the Dar es Salaam declaration of 1990 to protect and promote academic freedom (Kanywanyi, [14]); in addition, is the Kampala declaration of 1990 on academic freedom and social responsibility of academics (Mama, [15]). Article 7 of this declaration states that staff of the institutions of higher education have the right, directly and through their elected representatives, to initiate, participate in and determine academic programs of their institutions in accordance with the highest standards of education. Despite the above efforts, government interference and violation of the academic freedom of staff in developing nations is common because government claims the highest slot in funding these public institutions.

With academic freedoms, one can appeal to a higher value - the pursuit of truth - to argue that we must protect ideas that may be unpopular, controversial or without immediate practical benefit in order to support truth. More to that, one can argue that academic freedom is necessary to benefit human welfare which depends on the discovery and propagation of new knowledge. Since we cannot predict which knowledge will be helpful in the future, all new knowledge should be protected (Robinson and Moulton, [16]).

Academic freedom is therefore essential to the purpose and is justified on the basis of academic ground which is required for academic staff to teach and research without interference (Fuchs, [11]). Academic freedom also supports the establishment of their right which is a way of enabling the academic community to carry out their mission (Thorens, [17]). These assertions suggest that academic freedom is the pre-condition for the fulfilment of the choice of what to teach. This point of view indicates that academic freedom does not mean that academics can teach anything unrelated to the subject content, but how they freely adapt their freely chosen content areas to their professional understanding and opinions. Shils [8] avers that, the justification of academic freedom is that it protects the moral and intellectual integrity of the teacher. It protects the teacher's exercise of his or her intellectual powers in the search for and the exposition of truth.

Most writers primarily focus on the freedom of academic staff. Streb [18] observes that, academic freedom is the cornerstone of any university's mission to educate students and expand the boundaries of knowledge. The implication is that when academic staff is guaranteed, the transmission of knowledge will perfectly take place. According to Altbach ([19], p218), "the future of the university depends on a healthy climate for academic freedom". Academic freedom is a fundamental prerequisite for an effective University and a core value of higher education everywhere and for all types of academic institutions. Academic freedom is a complex and nuanced topic. Universities cannot achieve their potential nor fully contribute to the emerging knowledge-based society without academic freedom (Altbach, [12]). 
In this context, academic freedom is the fundamental principle for the University which enables it to contribute to the production and application of knowledge. The obligation of the institution is to protect that academic freedom, which must involve the officers of the institution actively doing so, and the academic staff similarly taking active part in making sure that it exists for all. The biggest challenge to safeguarding the freedom of academic community is the lack of agreement on the nature of academic freedom. As Altbach [20] asserts, the challenges to academic freedom in the $21^{\text {st }}$ century come not only from repressive external authorities but also from the new commercialism in higher education. The problems may also originate from within the institution due to the politicization of the academic community or tensions caused by religious or ethnic relations. Basing on different ideas offered by various scholars, the challenges to academic freedom can be categorized into two different sources which come from inside and/or outside the university. The political situation of the country and the government are external threats and academic staff and students themselves are internal threats to academic freedom (Caston, [2]). Altbach [19] explains that, there are many countries in which a considerable degree of academic freedom may exist for most scholars of the time, but where political or other crises may cause severe difficulties for the universities and for academic freedom, creating a general atmosphere of unease for many academics. In addition to these threats, the rights of academic community are restricted by some other factors. Shils [8] outlines that, the sanctions may range from arrest, imprisonment, torture, dismissal, withdrawal of the right to teach, expulsion from learned societies or refusal of admission to learned societies, censure by academic administrators, refusal of due promotion, and imposition of exceptional or onerous tasks, to personal abuse and the disruption of classes. This implies that academic freedom survives at the mercy of various institutional, social, political, and other bodies.

\section{THEORETICAL BASIS}

The special theory derives from the classical theory of academic freedom of the university. Searle [5] explains that, the classical theory of academic freedom, and the heart of any theory of academic freedom, is that professors should have the right to teach, conduct research, and publish their research without interference. The special theory of academic freedom emphasizes that academic staff have special rights which are concerned with the nature of the university. These rights are special rights that derive from particular institutional structures, which are created by quite specific sets of constitutive rules (Searle, [5]). Hook [21] argues that the right of academic freedom is not a general human right but it is a special right that must be earned. A human right, on the other hand, is a right that does not have to be earned. It is possessed by every human being for being so. In this regard, academic freedom in deciding what to teach is enjoyed conditionally on the basis of rules and standards of the university. This right needs to be granted either by the university or the constitution of the particular country to protect it from being violated and to enable freedom of decision on content. Knowledge is valuable and should be disseminated based on free inquiry (Searle, [5]; Shiell, [22]). The Special Theory is further strengthened by the General Theory which maintains the right to free expression and engagement in free discussion, free enquiry and free publication and dissemination of scholarly ideas. Therefore, members of academic staff have their rights as professionals and any attempt to interfere with those rights must be done in consideration of the rules and standards of the university (Searle, [5]).

\section{METHODS}

In order to fully appreciate the issue of academic staff' rights to decide what to teach, we analysed words, reports, detailed views of participants, and conducted the study in a natural setting. The study adopted a qualitative research in order to understand how people interpret their experiences, how they construct their world, and what meaning they attribute to their 
experiences as regards academic freedom. The study gathered in-depth data by using different methods ranging from observations and interviews with the primary intent of developing themes from the findings.

The Academic Staff of East African School of Higher Education Studies and Development (EASHESD) was our main focus. Two (2) members of academic staff were randomly picked to respond to some semi-structured interview questions meant to ascertain the perceptions of academic staff freedom to decide what to teach. They have been named A and B for purposes of anonymity. The selected participants' voices were not representative of the rest of the staff, but enabled to provide lenses through which we accessed the reality of the lecturer's freedom to decide what to teach.

The interview guide below was prepared on the basis of the aim of the study.

1. Based on your experience as a lecturer, what is your opinion on academic freedom?

2. Is it an absolute right for academic staff to decide what to teach? If so, how? Are there indicators of limited rights to decide what to teach? How are the rights limited?

3. What is the level of academic staff in designing the curriculum that you teach?

4. What are some of the threats hampering the freedoms of academic staff in choosing course content?

5. What mechanisms can be put in place to safe guard your academic freedom as academic staff?

\section{FINDINGS}

We sought their opinions about academic freedom of staff. Participant A emphasised that academic freedom is a requisite to academic staff to teach in their field of knowledge and expertise. The participant shared view with participant B in highlighting the need for the university to safeguard the freedom of academic staff to handle the content in a way that relates to the needs and interest of the learners. Participant B articulated the meaning of academic freedom as lecturers' freedom to choose the methods of teaching, what to teach, and carry out research on any topic of their interest and publish without restrictions.

Participant A intimated that it should be the right of academic staff to choose what to teach. Since they convene the programme, they should be able to express their expert and professional opinions related to the content during their interaction with learners. Participants $\mathrm{B}$ and $\mathrm{A}$, however expressed that unlike private institutions, Government institutions limit lecturers on the courses and content to be taught. The members of academic staff are not free to choose the course content that they want to teach because we have stipulated course for study. We cannot go beyond the course content. In public universities a course description is given to a lecturer to follow, and one has no right to adopt aspects that are not included in the course content.

Regarding the level of academic staff in designing the curriculum, participant B said that, the Board of every School sits and proposes course content to be included in the curriculum following the stipulations of the National Council for Higher Education (NCHE), an agency tasked by Government to oversee the academic processes and activities of higher education institutions. At this level, members of the faculty maybe asked to suggest areas to include. The suggestions are later studied and approved by the College Board after which they are forwarded to the University Senate for further study and approval. They are then submitted to the NCHE for final study and approval. In the process, a lot of changes take place. Some proposed content is adopted and some other may be dropped. It becomes hypocritical to 
attribute the final outcome to being the total proposal of the academic staff. Participant A added that members of academic staff simply play the role of developing course outline depending on the already designed course content. They research and translate the content into lectures to be given to students.

There are threats that hamper the freedom of academic staff in deciding on the content to teach. According to participant ' $A$ ', politics, donor agencies and the government interference are among these threats. Politics is the main stream of our country and every system is guided by politics. Worse still our political system is not stable and co-operative with the university especially when it comes to issues of funding university operations. Donor agencies also limit our operations to their desires. When agencies want a type of personnel to fill a particular human resource need, they suggest courses to that effect and make sure that all interactions with learners are geared towards producing that desired man power. The government interferes in the process of development and implementation of rules, reforms, policies and regulations of the university, which affect the freedoms of academic staff in higher Education. Participant B also outlined members of academic staff themselves, administrative responsiveness and students' behaviour. Most of them are members of different political parties, which is their right. However, they at times tend to extend their political thinking and actions to the daily operations of the university, which ultimately affect the whole programme of the university. This further affects the academic freedom of staff because freedom of expression whereby a lecturer may expression their own opinions during academic interactions with learners is done with fear of being misunderstood politically.

Participants A and B intimated that the university does not have a specific policy to safeguard academic freedom of academic staff. It could be that this is not the priority of the university, as participant B added. The negligence of the university is a major contributor to lack of such policy. Participant A stressed that there is lack of policy to safeguard academic freedom at the national level. They blamed it on the government which has not initiated the process of policy formulation on the subject of safeguarding academic freedom. The participant said that even if universities fail to make any policy on staff academic freedom, government still has the duty to develop policies and procedures which safeguard academic freedom within the framework of higher education institutions.

\section{DISCUSSIONS}

Perceptions of members of academic staff rhyme with scholars in acknowledging that academic freedom is perceived differently (Caston, [2]; Brown, [4]; Downs, [6]). However, they have some common facets that are general. They all underline the right of university academic staff and researchers to appropriately investigate fields of knowledge and express views without fear of restraint or reprisals. Academic freedom in the view of academic staff, is the fundamental right of expression, i.e. freedom to teach, freedom to research and freedom to publish. This view of academic freedom is related to the idea by Searle [5] in the general theory of academic freedom. Our findings show that members of academic staff perceive academic freedom in relation to teaching, learning and research. Academic freedom is the right of academic staff to teach, to carry out research, to participate in academic activities without any interference.

De George ([23], p.78) asserts that, "an academic staff's freedom may also be legitimately restricted in the content of a course". The findings indicate that members of academic staff in the context of this study are primarily involved in teaching activities. At least they exercise their right to teach, but are limited in the choice of content to teach. They do not fully take part in designing the course content and may not easily adopt new content as situation may suggest. 
They cannot alter the course content beyond the guidelines of the university and NCHE. Therefore, the right of academic staff to select the subject matter to teach according to the current needs of the learners is restricted (O'Hear, [7]).

On the factors affecting academic freedom, the analysis of the findings identifies some potential factors which affect the freedom of academic staff in choosing content. As some scholars (e.g. Caston, [2]; Altbach, [20]) indicate, there are factors which are external as they come from outside of the university. The findings indicated these as the political system, the government and the donor agencies. Other factors are internal because they come from within the university including academic staff, students and the administration which are part of those listed by Shils [8]. The findings indicate that the external factors are more serious challenges than the internal factors in exercising academic freedom of academic staff in deciding on content. The reason behind it is that the external factors directly interfere in the operation and management of the university as a result the university has no choice in the bid to offer academic freedom to its staff.

Academic staff suggested that the government needs to be responsible in safeguarding academic freedom. Firstly, the desire of the government is essential in order to protect academic freedom. Secondly, the government has to develop the rules and regulations regarding academic matters and provide the freedom to the university as well as academic staff in issues of deciding on content. As Akker [24] suggests, for academic freedom to be protected, universities must have considerable powers of academic and administrative selfgovernment. Similarly, the findings indicate that the university system is another sector to safeguard academic freedom in choosing content. Academic freedom is a practice within an institution (Pincoffs, [25]). The governing body of the university has to take the responsibility to develop essential terms and conditions to protect academic freedom and apply them in the university.

\section{CONCLUSION}

The study set out to understand the perceptions of academic staff, on academic freedom in deciding what to teach. The participants provided detailed perceptions in relation to academic freedom in choosing the content. The results indicate that academic freedom in choosing what to teach is essential for academic staff and remains their right. Professionally, freedom depends on fulfilling certain responsibilities, in this context, deciding on content to teach depending on the needs of learners and existing contextual dictates. Guaranteeing this academic freedom offers the positive motivation to academic staff to accomplish the mission of the university. This freedom makes them feel being in control of the knowledge they share with learners.

Academic freedom of academic staff is generally perceived as freedom to decide on how to teach, who to teach, what to teach, and the research to carry out without interference. However, our study concludes that this freedom is rhetoric. Although academic staff are primarily involved in teaching activities, they are restricted in the choosing the content they have to teach. Let alone the Kampala declaration of 1990, the study shows lack of institutional policy or a national legal document that encourages academic freedom and its legality. The discussion pointed out that the concept of academic freedom is neglected in the present constitution of the country. It is still not established as a part of legal system and no institutional policy on staff academic freedom has been developed by the governing bodies of the public institutions, e.g. University Council. In the absence of a policy or legal clause, it becomes hard to pursue academic freedom in deciding on what to teach or academic freedom of any form. 


\section{RECOMMENDATIONS}

The concept of academic freedom is itself new and challenging in some contexts. Basing on the study conclusions, there is need of establishing institutional policies and national regulations on the academic freedom of staff. Staff academic freedom should be a constitutional granted right. The study has based on the participants' voices to discover lack of commitment and motivation on the part of academic staff when they feel practicing at a robotic level. They would feel more confident if they have the freedom to make choices when doing their professional practices. Although their academic freedom to choose the content may be limited in as far as they have to keep to the NCHE stipulated content, ability to adjust the content to suit the needs of learners and current interactive situation should be encouraged.

It may be a limited right in opting for other content, but it remains a constitutional right to express oneself in a way that they feel proper provided it does not harm others. Therefore, freedom to express their intellectual opinions should be promoted. It creates a more critical environment and a society that accommodates different perspectives. This would gradually minimise external interferences and internal threats.

In most situations where government is the main financer of higher education, there is common emphasis put on doing things according to government interests. The institutions become more of propagators of political and national interests than pursuing intellectual visions. This is as well reflected in circumstances whereby financial agencies or private sector finances programmes. The desire for academic freedom may be hard to reach unless institutional freedom is achieved. Since the latter commonly ushers in the former, promoting free operation of higher education institutions is a highly necessary factor.

\section{References}

Euben, D. R. (2002). Academic Freedom of Individual Professors and Higher Education Institutions: The Current Legal Landscape. AAUP. org.

Caston, G. (2006). Academic freedom: The Third World context. Oxford Review of Education, 15(3), 305-338. doi: $10.1080 / 0305498890150310$

Ashby, E. (1966). Universities, British, Indian, African. Cambridge: Harvard University Press.

Brown, A. (2006). Academic freedom in Western Europe: Right or Privilege? In E.Gerstmann \& M. J. Streb (Eds.), Academic freedom at the dawn of a new century: How terrorism, governments and culture wars impact free speech (pp. 115-129). California: Stanford University Press.

Searle, J. (1972). The campus war. England: Penguin Books.

Downs, D. A. (2009). Academic freedom: What it is, what it isn't and how to tell the difference. Accessed on: http://www.popecenter.org/acrobat/AcademicFreedom.pdf

O'Hear, A. (1988). Academic freedom and the university. In M. Tight (Eds.), Academic Freedom and responsibility (pp. 6-16). Stony Stratford: Open University Press.

Shils, E. (1994). Do we still need academic freedom? Minerva, 32 (1), 79-98. doi:10.1007/BF01096657.

Lee F. (2015) Academic Freedom at American Universities, Washington, DC

Nelson, C. (2010). No university is an island: Saving academic freedom. New York: New York University Press.

Fuchs, R. F. (1963). Academic freedom - Its basic philosophy, function, and history. Law and Contemporary Problems, 28 (3), 431-446. Accessed on:

http://scholarship.law.duke.edu/cgi/viewcontent.cgi?article=2963\&context=lcp

Altbach, P. G. (2007). Academic freedom in a global context: $21^{\text {st }}$ century challenges. Accessed on: http://firgoa.usc.es/drupal/files/AcadFreedomNEA_2007.pdf

Adar, K. G. (1999). Human rights and academic freedom in Kenya's public universities: the case of the University's academic staff union. Human Rights Quarterly, 21(1), 179-206. 
Kanywanyi, J. L. (2006). Academic freedom, the autonomy of Institutions of higher education and the social responsibility of academics. Journal of Higher Education inAfrica/Revue` de l'enseignement supérieur en Afrique, 69-81.

Mama, A. (2006). Towards academic freedom for Africa in the $21^{\text {st }}$ century. Journal ofHigher Education in Africa/Revue de l'enseignement supérieur en Afrique, 1-32.

Robinson, G. \& Moulton, J. (2002). Plagiarism. Encyclopedia of ethics. Accessed on: http://sophia.smith.edu/ jmoulton/plagiarism.pdf

Thorens, J. P. (1998). Academic freedom and university autonomy. Prospects, 28(3), 401.

Streb, M. J. (2006). The re-emergence of the academic freedom debate. In E. Gerstmann \& M. J. Streb (Eds.), Academic freedom at the dawn of a new century: How terrorism, governments and culture wars impact free speech (pp. 3-16). California: Stanford University Press.

Altbach, P. G. (2001). Academic freedom: International realities and challenges. Higher Education, 41(1/2), 205219. Doi: $10.1023 /$ A: 1026791518365.

Altbach, P. (2015). Academic freedom: A realistic appraisal. International Higher Education,(57).

Hook, S. (1970). Academic freedom and academic anarchy. New York: Cowles.

Shiell, T. C. (2006). Three conceptions of academic freedom. In E. Gerstmann\& M. J. Streb (Eds.). Academic freedom at the dawn of a new century: How terrorism, governments and culture wars impact free speech (pp. 1740). California: Stanford University Press.

De George, R. T. (1997). Academic freedom and tenure: Ethical issues. United States of America: Rowman and Littlefield Publishers.

Akker, J. (2006). Academic freedom in the Middle East, Africa, and Asia: Looking toward the near future. In E. Gerstmann \& M. J. Streb (Eds.), Academic freedom at the dawn of a new century: How terrorism, governments and culture wars impact free speech (pp. 99-114). California: Stanford University Press.

Pincoffs, E. L. (1975). Introduction. In E. L. Pincoffs (Eds.), The concept of academic freedom (pp. vii-xxiv). United States of America: University of Texas Press. 